\title{
Deficiência da STAT5B: uma nova síndrome de insensibilidade ao hormônio de crescimento associada a acometimento imunológico
}

\author{
STAT5B deficiency: a new growth hormone insensitivity \\ syndrome associated to immunological dysfunction
}

Renata C. Scalco', Patrícia N. Pugliese-Pires' ${ }^{1}$ Alexander A. L. Jorge'

\begin{abstract}
SUMÁRIO
Uma nova apresentação da insensibilidade ao hormônio de crescimento (IGH), causada por mutações em homozigose no gene STAT5B (transdutor de sinal e ativador de transcrição tipo $5 B)$, foi caracterizada nos últimos anos. Sua particularidade é a associação com quadros de disfunção imunológica grave, sendo o mais característico a pneumonite intersticial linfocítica. A presença concomitante de doenças crônicas imunológicas pode fazer com que a baixa estatura seja erroneamente considerada uma consequência do quadro clínico, levando ao subdiagnóstico dessa forma de IGH. O objetivo desta revisão é divulgar o conhecimento atual sobre essa rara patologia, facilitando o reconhecimento de pacientes com IGH secundária a mutações no gene STAT5B em ambulatórios de endocrinologia e de outras especialidades. Arq Bras Endocrinol Metab. 2013;57(5):333-8
\end{abstract}

Descritores

STAT5B; baixa estatura; insensibilidade ao hormônio de crescimento; disfunção imunológica; autoimunidade

\section{SUMMARY}

A new presentation of growth hormone insensitivity $(\mathrm{GHI})$ caused by homozygous mutations in STAT5B (signal transducer and activator of transcription 5B) gene has been characterized in the last years. Its particularity is the association with severe immune dysfunction, especially with lymphocytic interstitial pneumonitis. This may mislead physicians into considering short stature as secondary to chronic immunological disease and consequently into underdiagnosing this form of $\mathrm{GHI}$. The objective of this review is to propagate current knowledge about this rare pathology, facilitating the diagnosis of patients with GHI due to STAT5B mutations in endocrinology and other specialties clinics. Arq Bras Endocrinol Metab. 2013;57(5):333-8

Keywords

STAT5B; short stature; growth hormone insensitivity; immune dysfunction; autoimmunity
Unidade de Endocrinologia Genética, LIM-25, Disciplina de Endocrinologia, Faculdade de Medicina da Universidade de São Paulo (FMUSP), São Paulo, SP, Brasil

\section{INTRODUÇÃO}

$\mathrm{O}$ sistema hormônio de crescimento (growth hormone - GH)/fator de crescimento insulina-símile tipo 1 (insulin-like growth factor 1 - IGF-1) é o principal determinante e regulador do crescimento linear. Um dos defeitos descritos no eixo GH/IGF-l é a insensibilidade ao hormônio de crescimento (IGH, OMIM: \#262500), definida como a inabilidade dos tecidos-alvo em responder normalmente à ação do GH (1).
A apresentação clássica da IGH, conhecida como síndrome de Laron, é caracterizada pela presença do fenótipo de deficiência de GH congênita (baixa estatura importante, fronte olímpica, hipoplasia de face, obesidade centrípeta, micropênis, hipoglicemia na infância) com dosagem de IGF-1 baixa e de GH alta ou inapropriadamente normal. No entanto, o quadro clínico e laboratorial da IGH varia dentro de um espectro que vai da síndrome de Laron a apresentações mais leves que 
podem ser confundidas com a baixa estatura idiopática (1). As causas mais comuns de IGH são mutações no gene do receptor de GH (GHR; OMIM: *600946), sendo que mais de setenta já foram descritas até o momento $(2,3)$, a maioria herdada de maneira autossômica recessiva $(3,4)$.

Em 2003, foi descrito o primeiro paciente com IGH causada por uma mutação inativadora em homozigose no gene da STAT5b (signal transducer and activator of transcription-5b gene - STAT5B; OMIM: *604260), uma molécula-chave na transdução do sinal via GHR (5). Desde então, nove outros casos foram descritos e foi observado que, além das características clínicas semelhantes às dos indivíduos com síndrome de Laron, pacientes com defeitos em homozigose no gene STAT5B também apresentam disfunção imunológica grave, que se manifesta tanto com quadros secundários à imunodeficiência, como infecções de repetição, quanto com eventos autoimunes como a pneumonite intersticial linfocítica. A disfunção imunológica parece ser justificada pelo defeito na ação da interleucina 2 (IL-2), envolvida na ativação dos linfócitos $\mathrm{T}$ e no desenvolvimento dos linfócitos T reguladores (Treg), e cuja sinalização intracelular também é dependente da STAT5b (6).

Pelo possível acometimento de diversos órgãos e sistemas, esses pacientes podem procurar serviços de múltiplas especialidades (Pneumologia, Infectologia, Imunologia, Dermatologia etc.). Assim, o objetivo desta revisão é divulgar esse diagnóstico ainda recente e pouco conhecido, facilitando o reconhecimento desses pacientes em ambulatórios de endocrinologia e de outras especialidades.

\section{PAPEL DA STAT5b NA SINALIZAÇÃO DO GH E INTERLEUCINAS}

O GH realiza suas ações por meio da ligação ao GHR, um receptor de membrana pertencente à família dos receptores de citocinas classe I (7) (Figura 1). O GHR possui um único domínio transmembrânico e não apresenta atividade enzimática intrínseca, devendo estar associado na sua porção intracitoplasmática a uma proteína com atividade de tirosina quinase conhecida como Janus quinase 2 (JAK2) para que ocorra a transdução do sinal intracelular. A ligação do GH a dois GHR que se encontram pré-dimerizados na superfície celular (8) promove uma alteração na conformação espacial da porção intracitoplasmática dos GHR, permitindo a fosforilação das JAK2. Uma vez fosforiladas, as JAK2 pas- sam a fosforilar múltiplos resíduos de tirosina presentes nos GHR, gerando sítios de acoplamento para outras moléculas sinalizadoras (8). Os GHR e as JAK2 ativam assim vias de sinalização comuns a vários receptores, como a via das quinases proteicas ativadas por mitógenos (MAPK) e a via do fosfatidilinositol 3-quinase (IP -3K), importantes para os efeitos metabólicos e para alguns efeitos proliferativos do GH. Além dessas vias, os receptores de citocinas possuem uma via de sinalização própria que utiliza proteínas citoplasmáticas conhecidas como STATs (7). Entre as sete STATs conhecidas até o momento, a que exerce papel principal na transdução do sinal do GHR em humanos é a STAT5b. Esta, quando fosforilada, forma um dímero e se transloca para o núcleo, onde sua ligação aos elementos responsivos aos dímeros da STAT5b no DNA leva à expressão de diversos genes como o da IGFl, de sua proteína ligadora (IGFBP-3) e da subunidade ácido-lábil (ALS) (9).

Outras moléculas que utilizam os receptores de citocina e consequentemente a via de sinalização das STATs incluem a prolactina, a eritropoetina, a trombopoetina, o fator estimulador de colônias de granulócitos (GCSF), o interferon gama e várias interleucinas, entre elas a IL-2 (10) (Figura 1). A ligação da IL-2 ao seu receptor leva à expressão via STAT5b de genes que incluem o FOXP3, que promove o desenvolvimento e função dos Treg, o IL2RA, que favorece a ativação de linfócitos $\mathrm{T}$, e genes que codificam os fatores antiapoptóticos Bcl-2 e Bcl-xL (6). Os Treg são essenciais no controle da resposta imune e na prevenção da autoimunidade (11) e a redução em seu número e função, vista em pacientes com mutações em homozigose no gene STAT5B (12), explica os quadros autoimunes encontrados. Já a maior suscetibilidade a infecções poderia ser justificada tanto por um aumento na apoptose de células $\mathrm{T}$ quanto por um defeito na ativação dos linfócitos T citotóxicos (6).

\section{MUTAÇÕES NO GENE STAT5B}

O gene STAT5B está localizado no cromossomo 17 q11.2 e é formado por dezenove éxons. Sua expressão é ubíqua e ele dá origem à proteína STAT5b, composta por 787 aminoácidos que se dividem em seis domínios: os domínios N-terminal e coiled-coil, responsáveis pelas interações proteína-proteína, um domínio de ligação ao DNA, uma região de ligação entre domínios sem função definida, um domínio de homologia a Src 2 (SH2), que permite a ligação das proteínas STAT 


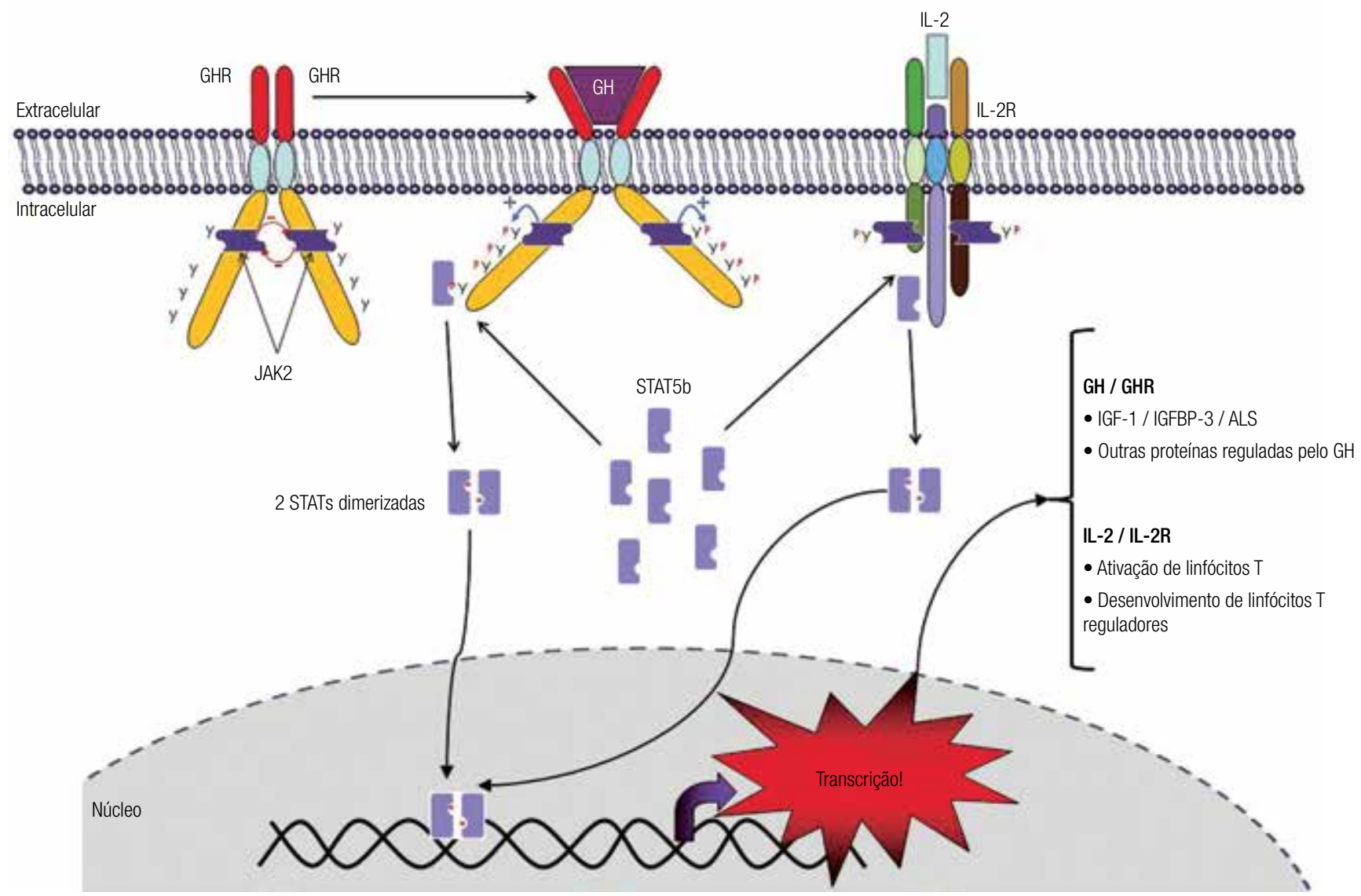

Figura 1. Papel da STAT5b na transdução do sinal do hormônio de crescimento (GH) e da interleucina-2 (IL-2). JAK 2 = janus quinase 2; STAT = signal transducer and activator of transcription; ALS = subunidade ácido-lábil; GH = hormônio de crescimento; IGF-1 = fator de crescimento insulina-símile tipo 1; IGFBP-3 = proteína 3 de ligação ao IGF; II-2R = receptor de IL-2.

a tirosinas fosforiladas de receptores ativados ou de outros peptídeos e a dimerização entre proteínas STATs, e um domínio C-terminal de transativação, crítico para a interação com outros fatores de transcrição $(9)$.

As sete mutações descritas até o momento distribuem-se de forma relativamente uniforme entre os éxons 5 e 17 (Figura 2). São duas deleções (c.424_427del/p.Leul42ArgfsX19 e c.1680delG/p. $\operatorname{Arg} 560$ ArgfsXl6) e duas inserções (c.1102insC/p. Gln368ProfsX9 e c.119linsG/p.Asn398GlufsX16), levando a uma alteração do quadro de leitura (mutação tipo frameshift), uma mutação tipo nonsense (c.454C>$\mathrm{T} / \mathrm{p} \cdot \operatorname{Arg} 152 \mathrm{X}$ ) e duas mutações do tipo missense (c. 1888G>C/p.Ala630Pro e c.1937T>C/p.Phe646Ser).

Dos dez pacientes descritos até o momento, dois são irmãos nascidos na cidade de Criciúma - Santa Catarina (13). Os pais dos meninos, heterozigotos para a mutação identificada nos filhos (c.424_427del), negam consanguinidade e, mesmo após revisão da genealogia de ambas as famílias por três gerações, não foram observados laços entre as famílias materna e paterna. Esse fato sugere que a mutação encontrada possa ser prevalente em heterozigose na região, possivelmente por um efeito fundador.

\section{CARACTERIZAÇÃO DOS PACIENTES COM MUTAÇÕES NO GENE STAT5B}

\section{Quadro clínico}

A herança é autossômica recessiva e houve confirmação de consanguinidade em três famílias. O comprimento e peso ao nascimento dos pacientes quando descritos foram normais ou pouco diminuídos para a idade gestacional, o que pode ser explicado pela relativa independência do crescimento pré-natal em relação ao GH. No entanto, o crescimento pós-natal foi muito comprometido, com padrão semelhante ao observado em pacientes com síndrome de Laron, e os escores $\mathrm{Z}$ de altura ao diagnóstico variaram entre -3,0 e -9,9 (Tabela 1). 


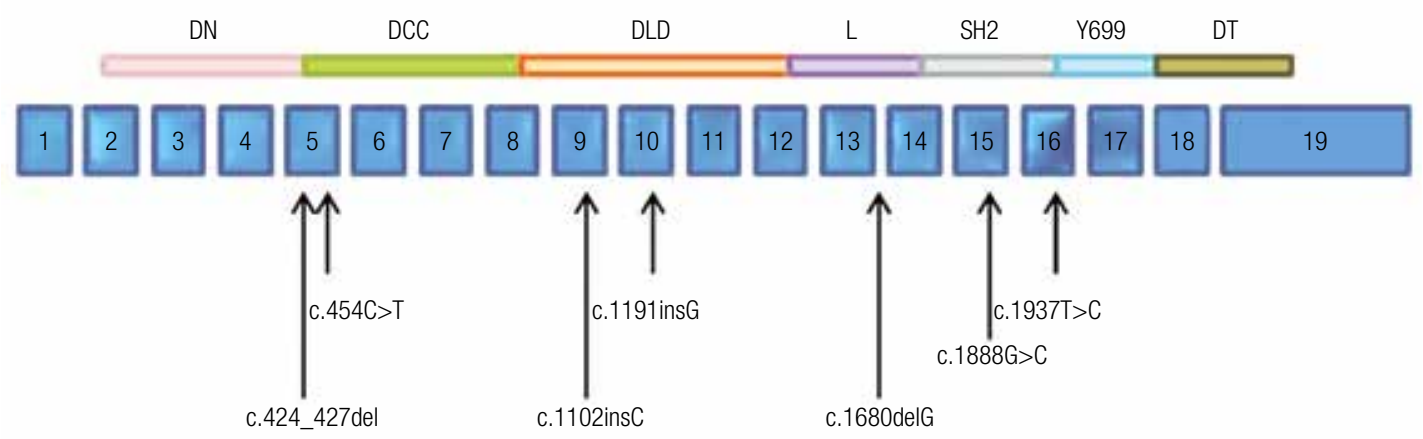

Figura 2. Representação dos 19 éxons do gene STAT5B, dos domínios da proteína STAT5b e das mutações descritas até o momento. DN: domínio N-terminal; DCC: domínio coiled-coil; DLD: domínio de ligação ao DNA; L: região ligante; SH2: domínio de homologia a Src 2; Y699: resíduo de tirosina fosforilado na ativação das STATs; DT: domínio C-terminal de transativação.

Tabela 1. Resumo dos principais achados clínicos dos pacientes com defeitos em homozigose no gene STAT5B descritos na literatura

\begin{tabular}{|c|c|c|c|c|c|c|c|c|c|c|}
\hline Paciente & 1 & 2 & 3 & 4 & 5 & 6 & 7 & 8 & 9 & 10 \\
\hline Mutações & C. $1888 \mathrm{G}>\mathrm{C}$ & c.1191insG & c. $454 C>T$ & c. $454 C>T$ & c.1102insC & \multicolumn{2}{|c|}{ c.1680delG } & c. $1937 \mathrm{~T}>\mathrm{C}$ & \multicolumn{2}{|c|}{ c.424_427del } \\
\hline Referência & (5) & (17) & (14) & (18) & (19) & \multicolumn{2}{|c|}{ (20) } & (21) & \multicolumn{2}{|c|}{ (13) } \\
\hline Sexo & $\mathrm{F}$ & $\mathrm{F}$ & $\mathrm{F}$ & $\mathrm{F}$ & M & $\mathrm{F}$ & $\mathrm{F}$ & $\mathrm{F}$ & $M$ & M \\
\hline País de origem & Argentina & Turquia & Argentina & Argentina & Caribe & \multicolumn{2}{|c|}{ Kuwait } & Argentina & \multicolumn{2}{|c|}{ Brasil } \\
\hline Altura mãe (cm) & 155,8 & 160 & 142,3 & ND & 165,6 & 160,2 & 160,2 & ND & 156 & 156 \\
\hline Altura pai (cm) & 173,6 & 169 & 160 & $N D$ & 164,3 & 167,7 & 167,7 & ND & 165 & 165 \\
\hline Consanguinidade & Sim & Sim & Não & Adotada & Não & Sim & Sim & Adotada & Não & Não \\
\hline Idade ao diagnóstico (anos) & 16,5 & 16,4 & 15,3 & 12 & 31 & 4 & 2 & 14,8 & 10,0 & 3,0 \\
\hline Z da altura ao diagnóstico & $-7,5$ & $-7,8$ & $-9,9$ & $-5,3$ & $-5,9$ & $-5,6$ & $-5,8$ & $-6,0$ & 5,6 & $-3,0$ \\
\hline Comprometimento pulmonar & Sim & Sim & Sim & Sim & Não & Sim & Não & Não & Sim & Sim \\
\hline Varicela grave & Sim & ND & Sim & Sim & Sim & ND & ND & Sim & Sim & Não \\
\hline Eczema grave & ND & Sim & Sim & Sim & Sim & ND & ND & Sim & Sim & Sim \\
\hline Outras manifestações & $\operatorname{Sim}^{1}$ & $\mathrm{Sim}^{2}$ & $\mathrm{Sim}^{3}$ & $\mathrm{Sim}^{4}$ & Não & $\operatorname{Sim}^{5}$ & $\operatorname{Sim}^{6}$ & $\mathrm{Sim}^{7}$ & Não & Sim \\
\hline
\end{tabular}

ND: não disponível. As pacientes 6 e 7 são irmãs e os pacientes 9 e 10 são irmãos. Outras manifestações: 1. Herpes zoster recorrente; 2. Infecções pulmonares de repetição, diátese hemorrágica; 3. Infecções de repetição em pele, trato respiratório e trato gastrointestinal, ceratite e uveíte recorrentes por herpes zoster; 4. Sepse neonatal, diarreia crônica, ceratite, herpes zoster, tireoidite autoimune, displasia ectodérmica disidrótica, infecções pulmonares de repetição; 5. Infecções pulmonares de repetição, bronquiectasia; 6 . Artrite reumatoide juvenil; 7. Infecções de repetição, tireoidite autoimune; 8. Púrpura trombocitopênica idiopática.

Na maioria dos casos foram relatadas características fenotípicas de IGH, como fronte olímpica, hipoplasia de face e voz aguda. A puberdade foi atrasada em sete dos oito pacientes que atingiram idade para seu início, provavelmente pelo IGF-1 baixo e estado de doença crônica. A idade óssea também estava atrasada em todos os casos em que foi relatada. O desenvolvimento cognitivo foi normal nos pacientes em que foi descrito.

\section{Alterações imunológicas}

Sete dos dez pacientes apresentaram quadro de doença pulmonar crônica grave e de início precoce (Tabela 1). O diagnóstico (confirmado por biópsia pulmonar em alguns pacientes e presuntivo em outros) foi de pneumonite intersticial linfocítica, uma patologia de etiologia desconhecida, rara em crianças e frequentemente associada a doenças autoimunes. Essa doença causa fibrose pulmonar progressiva, sendo que duas pacientes faleceram por insuficiência respiratória e um foi submetido a transplante pulmonar, até o momento com boa evolução (13). Outras manifestações relatadas foram varicela grave/hemorrágica em seis pacientes e eczema grave em outros sete. Além disso, a maioria dos pacientes tem história de infecções de repetição. Foram descritos também dois casos de tireoidite autoimune, um caso de artrite reumatoide juvenil de início precoce (diagnóstico aos dois anos de idade) e um caso de púrpura trombocitopênica (Tabela 1). 


\section{Alterações laboratoriais}

Os pacientes apresentaram GH basal normal ou elevado, em geral com aumento importante durante teste de estímulo. Dosagens de IGF-1, IGFBP-3 e ALS foram invariavelmente baixas e não houve aumento nos casos em que se fez teste de geração com rhGH (Tabela 2). A proteína de ligação ao GH (GHBP) foi sempre normal, ao contrário do que acontece na maioria dos pacientes com mutação do GHR. A prolactina foi elevada em seis dos sete pacientes em que foi dosada, provavelmente por uma interferência com seu mecanismo de retroalimentação negativa pela mutação no gene $\operatorname{STAT5B}(13)$.

Em relação à avaliação imunológica não existe um padrão tão claro como no perfil hormonal. Dos seis pacientes avaliados, quatro apresentaram hipergamaglobulinemia e cinco tinham linfopenia de células $\mathrm{T}$. Quatro dos pacientes também apresentavam redução dos linfócitos natural killer (NK). Em uma das pacientes, foi realizado estudo in vitro que mostrou baixa proliferação dos linfócitos $\mathrm{T}$ em resposta a mitógenos e antígenos, documentando uma disfunção generalizada nessas células (14). Foi sugerido também que a hipergamaglobulinemia poderia ser resultado de uma desregulação das células B secundária a um controle inadequado destas pelas células $\mathrm{T}$ disfuncionais (14).

\section{Tratamento}

Em relação à baixa estatura, não houve resposta à terapia com $\mathrm{GH}$ recombinante humano $(\mathrm{rhGH})$ em pacientes com mutações no gene STAT5B, assim como ocorre nos indivíduos com IGH secundária a mutações no GHR. O tratamento com IGF-1 recombinante humano (rhIGF-1) é aprovado para crianças com deficiência primária grave de IGF-1, o que inclui pacientes com IGH (15). Em pessoas com IGH causada por mutações no $G H R$, essa terapia já foi avaliada e um dos estudos, en- volvendo 76 indivíduos tratados, mostrou um incremento mediano na velocidade de crescimento do primeiro ano de tratamento de $5,3 \mathrm{~cm} /$ ano (16). No entanto, nos dois irmãos brasileiros foi tentada a terapia com rhIGF-1 e não se notou melhora do padrão de crescimento, possivelmente pelo estado de doença crônica (13).

Também não existe um tratamento específico para a disfunção imunológica até o momento. Foi sugerida a possibilidade de transplante de medula óssea para corrigir a deficiência de células $\mathrm{T}$ nos pacientes com mutações no gene $S T A T 5 B$, porém este ainda não foi realizado em nenhum dos pacientes descritos.

\section{CONSIDERAÇÕES FINAIS}

O diagnóstico de IGH secundária a mutações no gene STAT5B deve ser suspeitado em pacientes com quadro de IGH e alterações imunológicas, especialmente quando há linfopenia de células $\mathrm{T}$ e/ou hiperprolactinemia. O estudo molecular do gene STAT5B permite a confirmação dessa condição. Como os pacientes com mutações na STAT5B têm doenças imunológicas graves e de início precoce, sua baixa estatura pode ser erroneamente considerada consequência do processo inflamatório crônico, levando ao subdiagnóstico dessa patologia. Diagnosticar adequadamente esses pacientes é o primeiro passo para a ampliação do conhecimento sobre essa forma mais rara de IGH, permitindo no futuro a descoberta de um tratamento específico para essa síndrome.

Agradecimentos: este trabalho obteve apoio da Fundação de Amparo à Pesquisa do Estado de São Paulo (Fapesp): processos 2011/15078-0 para Renata C. Scalco e 2010/19809-6 para Alexander A. L. Jorge; e do Conselho Nacional de Desenvolvimento Científico e Tecnológico (CNPq): n ${ }^{\circ}$ 304678/2012-0 para Alexander A. L. Jorge.

Declaração: os autores declaram não haver conflitos de interesse científico neste estudo.

Tabela 2. Resumo dos principais achados laboratoriais dos pacientes com defeitos em homozigose no gene STAT5B descritos na literatura

\begin{tabular}{lcccccccccc}
\hline Paciente & $\mathbf{1}$ & $\mathbf{2}$ & $\mathbf{3}$ & $\mathbf{4}$ & $\mathbf{5}$ & $\mathbf{6}$ & $\mathbf{7}$ & $\mathbf{8}$ & $\mathbf{9}$ & $\mathbf{1 0}$ \\
\hline Mutações & c.1888G>C & c.1191insG & c.454C>T & c.454C>T & c.1102insC & c.1680delG & c.1937T $>$ C & c.424_427del \\
Referência & $(5)$ & $(17)$ & $(14)$ & $(18)$ & $(19)$ & & $(20)$ & $(21)$ & $(13)$ \\
GH basal (ng/ml) & 9,4 & 14,2 & 4,2 & 1,8 & 0,1 & 5,7 & 17,7 & ND & 1,7 & 1,0 \\
Escore Z IGF-1 & $<-3$ & $<-3$ & Indetectável & $<-3$ & $-8,2$ & $<-3$ & $<-3$ & Indetectável & $<-3$ & $<-3$ \\
PRL (ng/ml) & 102 & ND & 169 & 15 & 110 & ND & ND & 83 & 61 & 77 \\
IgG & Aumentada & Aumentada & Aumentada & ND & ND & ND & ND & Aumentada & Aumentada & Normal \\
Linfócitos T & Reduzidos & Normais & Reduzidos & ND & ND & ND & ND & Reduzidos & Reduzidos & Reduzidos \\
Linfócitos NK & Normais & Normais & Reduzidos & ND & ND & ND & ND & Reduzidos & Reduzidos & Reduzidos \\
\hline
\end{tabular}

ND: não disponível. Linfócitos NK: linfócitos natural killer. As pacientes 6 e 7 são irmãs e os pacientes 9 e 10 são irmãos. 


\section{REFERÊNCIAS}

1. Jorge AA. [Short stature investigation: clinical, laboratorial and genetic aspects concerning the growth hormone insensitivity (GHI)]. Arq Bras Endocrinol Metabol. 2008;52(6):1056-65.

2. Diniz ET, Jorge AA, Arnhold IJ, Rosenbloom AL, Bandeira F. [Novel nonsense mutation (p.Y113X) in the human growth hormone receptor gene in a Brazilian patient with Laron syndrome]. Arq Bras Endocrinol Metabol. 2008;52(8):1264-71.

3. David A, Hwa V, Metherell LA, Netchine I, Camacho-Hubner C, Clark AJ, et al. Evidence for a continuum of genetic, phenotypic, and biochemical abnormalities in children with growth hormone insensitivity. Endocr Rev. 2011;32(4):472-97.

4. Jorge AA, Souza SC, Arnhold IJ, Mendonca BB. The first homozygous mutation (S226I) in the highly-conserved WSXWS-like motif of the $\mathrm{GH}$ receptor causing Laron syndrome: supression of $\mathrm{GH}$ secretion by $\mathrm{GnRH}$ analogue therapy not restored by dihydrotestosterone administration. Clin Endocrinol (Oxf). 2004;60(1):36-40.

5. Kofoed EM, Hwa V, Little B, Woods KA, Buckway CK, Tsubaki J, et al. Growth hormone insensitivity associated with a STAT5b mutation. N Engl J Med. 2003;349(12):1139-47.

6. Casanova JL, Holland SM, Notarangelo LD. Inborn errors of human JAKs and STATs. Immunity. 2012;36(4):515-28.

7. Kopchick JJ, Andry JM. Growth hormone (GH), GH receptor, and signal transduction. Mol Genet Metab. 2000;71(1-2):293-314.

8. Waters MJ, Brooks AJ. Growth hormone receptor: structure function relationships. Horm Res Paediatr. 2011;76 Suppl 1:12-6.

9. Hwa V, Nadeau K, Wit JM, Rosenfeld RG. STAT5b deficiency: lessons from STAT5b gene mutations. Best Pract Res Clin Endocrinol Metab. 2011;25(1):61-75.

10. Nadeau K, Hwa V, Rosenfeld RG. STAT5b deficiency: an unsuspected cause of growth failure, immunodeficiency, and severe pulmonary disease. J Pediatr. 2011;158(5):701-8.

11. Burchill MA, Yang J, Vang KB, Farrar MA. Interleukin-2 receptor signaling in regulatory $T$ cell development and homeostasis. Immunol Lett. 2007;114(1):1-8.

12. Cohen AC, Nadeau KC, Tu W, Hwa V, Dionis K, Bezrodnik L, et al. Cutting edge: decreased accumulation and regulatory function of
CD4+ CD25(high)T cells in human STAT5b deficiency. J Immunol. 2006;177(5):2770-4.

13. Pugliese-Pires PN, Tonelli CA, Dora JM, Silva PC, Czepielewski M, Simoni G, et al. A novel STAT5B mutation causing GH insensitivity syndrome associated with hyperprolactinemia and immune dysfunction in two male siblings. Eur $\mathrm{J}$ Endocrinol. 2010;163(2):349-55.

14. Bernasconi A, Marino R, Ribas A, Rossi J, Ciaccio M, Oleastro $M$, et al. Characterization of immunodeficiency in a patient with growth hormone insensitivity secondary to a novel STAT5b gene mutation. Pediatrics. 2006;118(5):e1584-92.

15. Collett-Solberg PF, Misra M. The role of recombinant human insulin-like growth factor-l in treating children with short stature. J Clin Endocrinol Metab. 2008;93(1):10-8.

16. Chernausek SD, Backeljauw PF, Frane J, Kuntze J, Underwood LE. Long-term treatment with recombinant insulin-like growth factor (IGF)-I in children with severe IGF-I deficiency due to growth hormone insensitivity. J Clin Endocrinol Metab. 2007;92(3):902-10.

17. Hwa V, Little B, Adiyaman P, Kofoed EM, Pratt KL, Ocal G, et al. Severe growth hormone insensitivity resulting from total absence of signal transducer and activator of transcription $5 \mathrm{~b}$. J Clin Endocrinol Metab. 2005;90(7):4260-6.

18. Boyanovsky A, Lozano A, Testa G, editors. Growth hormone insensitivity and immunodeficiency: mutation in the STAT5B gene. 8th Joint Meeting of the Lawson Wilkins Pediatric Endocrine Society/European Society for Paediatric Endocrinology; 2009.

19. Vidarsdottir S, Walenkamp MJ, Pereira AM, Karperien M, van Doorn J, van Duyvenvoorde HA, et al. Clinical and biochemical characteristics of a male patient with a novel homozygous STAT5b mutation. J Clin Endocrinol Metab. 2006;91(9):3482-5.

20. Hwa V, Camacho-Hubner C, Little BM, David A, Metherell LA, ElKhatib N, et al. Growth hormone insensitivity and severe short stature in siblings: a novel mutation at the exon 13-intron 13 junction of the STAT5b gene. Horm Res. 2007;68(5):218-24.

21. Martinez A, Scaglia PA, Rivas M. Novel STAT5b gene mutation in a patient presenting $\mathrm{GH}$ insensitivity and immunodeficiency. Horm Res. 2007;68(suppl 1):33. 